\section{Seminars in Child and Adolescent Psychiatry (2nd edn) \\ Simon G. Gowers (ed.) \\ London: Gaskell, 2005, £25.00, \\ pp. 370. \\ ISBN 1904671136}

The publication of the second editions of the Gaskell seminar series represents a minor milestone in the evolution of College postgraduate education. Written under the auspices of the College, the books have become an unofficial syllabus for those taking their Membership examination and in sub-specialty training. According to the Foreword, the series are 'all the College requires the trainee to know about a sub-specialty, and a little bit more.' The involvement of several chapter authors of Seminars in Child and Adolescent Psychiatry with the College training advisory committee ensures the book's direct relevance. I used the first edition, edited by David Cottrell and Dora Black, as part of my own Membership revision. It is rather sobering to be reviewing the next edition 12 years later.

The strengths of the book are its brevity and concision. The opening chapters cover the development of the child and the specialty, adult continuity and classification. The chapter on assessment is to be commended for its clarity and for the inclusion of physical examination, a core skill which is often neglected both in texts and in practice. The next 100 pages cover the main psychiatric disorders of childhood in logical sequence, but with the inexplicable omission of chapters on attention-deficit hyperactivity disorder and tic disorder. These are covered in passing in a later chapter covering biological factors. Aspects of treatment are described in the final 100 pages.

The book reads well although the variety of authors means some stylistic differences and the duplication of some material. Some chapters read like revision aids and others like essays. The illustrations and tables help to break up the text and the examples of paintings by children of different ages are helpful. The choice of the rather macabre pictures that accompany the opening chapter is questionable.

Survey of my colleagues suggests that today's community consultant child and adolescent psychiatrist needs to contribute skills in neurodevelopmental diagnosis and pharmacotherapy to the team. I understand that in this style of book space is short, but I found these aspects to be insufficiently covered. This is a successful update of the first edition which will be popular among trainees, but the third edition will have to tackle the gaps as the specialty continues to evolve.
Gordon Bates Consultant Child and Adolescent Psychiatrist, Parkview Clinic, Birmingham Children's Hospital NHS Trust, Birmingham B13 9UD, email: gordon.bates@bch.nhs.uk

\section{Menopause: A Mental Health Practitioner's Guide}

Donna E. Stewart (ed)

Washington, DC: American

Psychiatric Publishing, 2005,

$\$ 34.95, \mathrm{pb}, 202 \mathrm{pp}$

ISBN: 1-58562-160-9

The menopause is a significant biological event in the life of every woman and menopausal transition has been often associated with an increase in physical and mental health complaints. However, there is little clarity of thought on the subject. Although some groups tend to medicalise psychosocial issues and human suffering, others minimise or completely ignore serious mood and endocrinological disorders.

In the past decades there has been a wealth of research on the physical and psychological aspects of the menopausal period. However, several multi-author books on women's mental health have failed to effectively deal with the issues during and after the menopause.

This is one of the few books that has focused solely on this period and has an objective and balanced view. The book has eight thought-provoking chapters covering all aspects of menopausal problems. The first chapter introduces the context of midlife and the following two chapters describe the physiology and the effects of reproductive hormones. The chapters on mood disorders and psychotic illness in the perimenopausal period address many of the questions of practising psychiatrists. These chapters are easy to read, well written and unpretentious. The chapters on the medical and gynaecological aspects of the menopause and the perimenopause set the scene for a wider understanding of the impact of the changes which take place in the body. The last chapter describes probably the most neglected aspect of all, the psychopathology and the psychotherapeutic needs beyond the menopause.

The authors introduce the reader to the multitude of interconnected problems that affect the menopausal woman. They contribute to the recognition of the common problems and bring clear answers to questions frequently asked by both medical and non-medical professionals. This is a positive and considered book and a genuine contribution to the understanding of the menopausal period. It has a clear message and an invaluable collection of information. It explores current practice and reviews the changes necessary to improve practice. The book would be useful for general practitioners, psychiatrists and all involved in the assessment of menopausal and postmenopausal women.

Dora Kohen Psychiatric Department, University of Central Lancashire, Mental Health Management Block, Leigh Infirmary, Leigh WN7 1HS, email: dorakohen@doctors.org.uk

\section{Partners in Care Training Resource}

Mike McClure (ed.) London: Royal College of Psychiatrists, 2005, f45.00, 256 sheets in ring-binder+ CD-ROM, ISBN: 1904671284

This book is timely, as the recognition and assessment of carers' needs is still erratic within many areas of mental health. It deals comprehensively with issues relating to developing partnerships between carers, users and mental health professionals. The key themes are the recognition and understanding of the needs of carers and service users, the provision of relevant information and the participation of carers and users in training. The issue of confidentiality, which is frequently seen as a barrier to partnership working, is dealt with pragmatically. It was particularly reassuring to note the chapter on young carers and families, as this is an area that is increasingly recognised within mental health. In addition, the contribution of carers' own stories is both poignant and helps to provide insight into their shared experiences.

All six chapters are of interest and the training resource can be adapted to the training needs of individuals. Practical guidance and teaching material is supplied both in hard copy and on the CD-ROM. In addition there are checklists for good practice that will ensure relevant information is provided consistently to users and carers across specialties. For those that prefer not to complete forms, these checklists are helpful as an aide-memoire.

Criticisms of the book include the poor editing and the frequent repetition of information and learning objectives. However, as the book is unlikely to be read as a whole this should not matter. Partners in Care is an excellent example of collaborative working between two key organisations (the Royal College of Psychiatrists and the Princess Royal Trust for Carers). Overall it is a useful, wellconstructed book that provides a concise and practical guide to improving partnership working with carers and service users. Although primarily aimed at psychiatrists, this training manual is clearly a much-needed resource for all mental health professionals and organisations. 